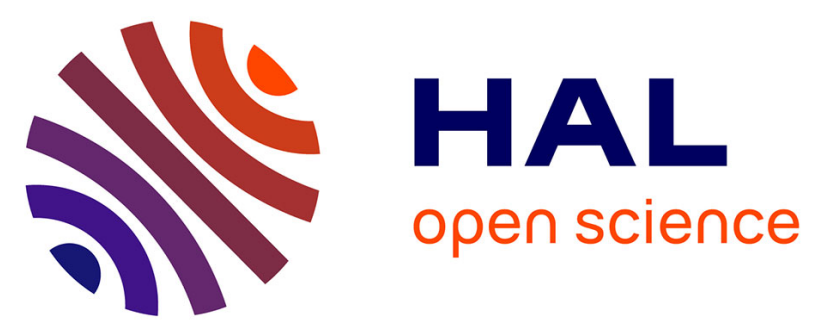

\title{
The host plant Pinus pinaster exerts specific effects on phosphate efflux and polyphosphate metabolism of the ectomycorrhizal fungus Hebeloma cylindrosporum: a radiotracer, cytological staining and 31P NMR spectroscopy study
}

Margarita Torres-Aquino, Adeline Becquer, Christine Le Guernevé, Julien Louche, Laurie Amenc, Siobhan Staunton, Herve Quiquampoix, Claude Plassard

\section{To cite this version:}

Margarita Torres-Aquino, Adeline Becquer, Christine Le Guernevé, Julien Louche, Laurie Amenc, et al.. The host plant Pinus pinaster exerts specific effects on phosphate efflux and polyphosphate metabolism of the ectomycorrhizal fungus Hebeloma cylindrosporum: a radiotracer, cytological staining and 31P NMR spectroscopy study. Plant, Cell and Environment, 2017, 40 (2), pp.190-202. 10.1111/pce.12847 . hal-01837808

\section{HAL Id: hal-01837808 \\ https://hal.science/hal-01837808}

Submitted on 27 May 2020

HAL is a multi-disciplinary open access archive for the deposit and dissemination of scientific research documents, whether they are published or not. The documents may come from teaching and research institutions in France or abroad, or from public or private research centers.
L'archive ouverte pluridisciplinaire HAL, est destinée au dépôt et à la diffusion de documents scientifiques de niveau recherche, publiés ou non, émanant des établissements d'enseignement et de recherche français ou étrangers, des laboratoires publics ou privés. 
The host plant Pinus pinaster exerts specific effects on phosphate efflux and polyphosphate metabolism of the ectomycorrhizal fungus Hebeloma cylindrosporum: a radiotracer, cytological staining and ${ }^{31} \mathrm{P}$ NMR spectroscopy study

Running title: $\mathrm{P}$ efflux and polyP dynamics of $H$. cylindrosporum

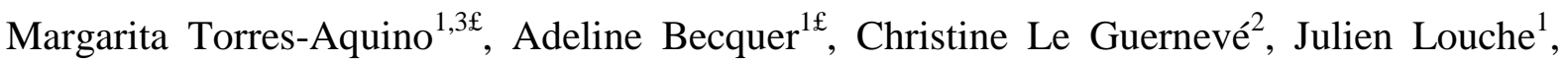
Laurie K Amenc ${ }^{1}$, Siobhan Staunton ${ }^{1}$, Hervé Quiquampoix ${ }^{1} \&$ Claude Plassard ${ }^{1 *}$

Author's affiliations

${ }^{1}$ INRA, UMR Eco\&Sols, 2 place Viala, 34060 Montpellier, Cedex 1, France

${ }^{2}$ INRA, UMR SPO (1083) Sciences pour 1'Oenologie, 2 place Viala, 34060 Montpellier, Cedex 1, France

${ }^{3}$ Present address: Colegio de Postgraduados, Campus San Luis Potosí, Agustín de Iturbide $N^{\circ} 73$, Salinas de Hidalgo, Salinas, S.L.P, México, CP 78600

*Corresponding author: Dr Claude PLASSARD

INRA, UMR Eco\&Sols

2, place Pierre Viala

34060 Montpellier Cedex 1 - France

Tel: +33499612979

Fax: +33499612 119

Footnotes

Margarita Torres-Aquino fellowship Ph-D was funded by CONACYT (Mexico). Adeline Becquer was supported by a fellowship from INRA (France) through a Contract for Young Scientist (CJS) and Julien Louche by a Ph-D grant from the French Minister of Research and Technology. The authors declare no conflict of interest.

${ }^{\mathrm{f}}$ These authors contributed equally to the work

* Corresponding author; e-mail: claude .plassard@supagro.inra.fr

This article has been accepted for publication and undergone full peer review but has not been through the copyediting, typesetting, pagination and proofreading process which may lead to differences between this version and the Version of Record. Please cite this article as doi:

This article is protected by copyright. All rights reserved. 


\begin{abstract}
Ectomycorrhizal (ECM) association can improve plant phosphorus (P) nutrition. Polyphosphates (polyP), synthesized in distant fungal cells after $\mathrm{P}$ uptake may contribute to $\mathrm{P}$ supply from the fungus to the host plant if they are hydrolyzed to phosphate in ECM roots then transferred to the host plant when required. In this study, we addressed this hypothesis for the ECM fungus Hebeloma cylindrosporum grown in vitro and incubated without plant or with host (Pinus pinaster) and non-host (Zea mays) plants, using an experimental system simulating the symbiotic interface. We used ${ }^{32} \mathrm{P}$ labelling to quantify $\mathrm{P}$ accumulation and $\mathrm{P}$ efflux and in vivo and in vitro NMR spectroscopy and cytological staining to follow the fate of fungal polyP. Phosphate supply triggered a massive $\mathrm{P}$ accumulation as newly synthesized long-chain polyP in $H$. cylindrosporum if previously grown under P-deficient conditions. $\mathrm{P}$ efflux from $H$. cylindrosporum towards the roots was stimulated by both host and non-host plants. However, the host plant enhanced ${ }^{32} \mathrm{P}$ release compared to the non-host plant and specifically increased the proportion of short-chain polyP in the interacting mycelia. These results support the existence of specific host-plant effects on fungal $\mathrm{P}$ metabolism able to provide $\mathrm{P}$ in the apoplast of ectomycorrhizal roots.
\end{abstract}

Summary

In this work we examined whether a host or a non-host ectomycorrhizal (ECM) plant can enhance $\mathrm{P}$ efflux and affect polyphosphate (polyP) metabolism of an ECM fungus. In a system simulating the symbiotic interface in vitro, we used ${ }^{32} \mathrm{P}$ to quantify $\mathrm{P}$ fluxes and ${ }^{31} \mathrm{P}$ NMR to follow the fate of fungal polyP. For the first time, this paper shows that an ECM host plant has a direct effect on polyP hydrolysis to promote fungal Pi release.

Keywords: Pinus pinaster, Zea mays, Hebeloma cylindrosporum, fungal $\mathrm{P}$ efflux, polyphosphates, ${ }^{32} \mathrm{P}$ labelling, in vivo ${ }^{31} \mathrm{P}$ NMR spectroscopy. 


\section{Introduction}

Ectomycorrhizal (ECM) symbiosis is a mutual association between fungal symbionts and lateral roots of trees. This symbiosis is the most widespread association in temperate and boreal biomes where it is formed by $95 \%$ of forest trees (Smith \& Read 2008). ECM fungi are known to stimulate host plant growth, mainly by enhancing soil nutrient uptake. The positive effect of ECM symbiosis on plant phosphorus $(\mathrm{P})$ nutrition has been demonstrated (Smith \& Read 2008; Plassard \& Dell 2010; Cairney 2011; Smith et al. 2015) although more knowledge is available regarding the effect of ECM fungi on plant nitrogen $(\mathrm{N})$ nutrition (Smith et al. 2015). The positive effect on phosphate (Pi) uptake has been attributed primarily to the external mycelium of the fungus that functions as an extension of the root system allowing the exploration of a larger volume of soil beyond the depletion zone formed around actively absorbing roots (Smith \& Read 2008; Cairney 2011; Smith et al. 2015). Pi is absorbed from the soil solution by Pi transporters in the extraradical hyphae (Tatry et al. 2009). Once absorbed, Pi may be incorporated in the active $\mathrm{P}$ fungal pool, including phosphorylated primary metabolites, structural molecules and nucleic acids necessary for fungal growth and metabolism or transferred to the host-plant, as demonstrated by pioneer labelling experiments (Melin \& Nilsson 1950). Pi can also be transferred to the vacuoles and condensed into polyphosphates (polyP) to constitute a storage pool (Ashford et al. 1994, 1999). Cairney (2011) proposed a model of ECM functioning, and suggested that these polyP are probably translocated to the host via a motile tubular vacuolar system (Ashford \& Allaway 2002; Darrah et al. 2006; Bücking \& Heyser 1999) before being hydrolyzed within the Hartig net to provide Pi efflux from the fungal cells to the interfacial apoplast. Pi could then be recovered by some plant $\mathrm{P}$ transporters whose expression is enhanced in ECM roots (Loth-Pereda et al. 2011; Kariman et al. 2014) or in host cells containing arbuscules (Harrison et al. 2002; Loth-Pereda et al. 2011; Rausch et al. 2001; Volpe et al. 2016) in arbuscular mycorrhizal (AM) plants.

The synthesis of polyP by the ECM fungi appears therefore to be a key element of mycorrhizal functioning. In living systems, linear inorganic polyP may contain up to $1000 \mathrm{Pi}$ units (Wood \& Clark 1988). Chen (1999) proposed the classification of polyP as short-chain (chain length $<20$ units) or long-chain (chain length $>50$ units). To date, several methods have been used to reveal and to analyze polyP in cells. For example in vivo NMR spectroscopy of ${ }^{31} \mathrm{P}$ can give information on the forms and locations of $\mathrm{P}$ metabolites by detecting freely mobile inorganic phosphorus in the living cells such as orthophosphate and 
polyphosphate, and small organic phosphate metabolites (esters of phosphate or phosphonate). PolyP occurrence in ECM fungi has been intensively studied (reviewed by Pfeffer et al. 2001) and, when grown in vitro, the chain length of NMR-visible polyP ranged from 11 to $15 \mathrm{P}$ residues (Martin et al. 1983, 1985; Ashford et al. 1994), suggesting that the polyPs visible by in vivo ${ }^{31} \mathrm{P}$ NMR are mainly short-chain polyP. In addition to ${ }^{31} \mathrm{P} \mathrm{NMR}$, polyPs can be observed as metachromatic granules following the application of cationic dyes such as toluidine blue $\mathrm{O}$ to chemically fixed and dehydrated samples (Chilvers et al. 1985; Ashford et al. 1986, 1999). Energy dispersive X-ray microanalysis applied to cryofixed material showed spherical electron-opaque deposits containing high amounts of $\mathrm{P}$ associated with potassium (K) (Bücking \& Heyser 2000). Both structures are localized in the vacuoles of ECM fungi and have been defined as polyP granules (Chilvers et al. 1985; Ashford et al. 1986; Bücking \& Heyser 1999). In contrast to ${ }^{31} \mathrm{P}$ NMR, the latter methods can reveal either mobile or immobile polyP consisting of short- and long-chain polyP.

Within the Hartig net of ECM roots, where the exchanges between the fungal and the host cells take place, there is no direct symplastic continuity between both partners. Therefore, $\mathrm{Pi}$ must pass through the interfacial apoplast before it can be absorbed (Peterson \& Bonfante 1994). P transfer from fungal hyphae must be sufficient to meet host plant demand (Smith \& Smith 1990). Such conditions would therefore be a prerequisite for effective symbiotic association. $\mathrm{P}$ efflux rates have been measured from fungal hyphae grown in vitro but their values were much lower than the flows of $\mathrm{P}$ across the apoplasmic space and the estimated $\mathrm{P}$ influx rates into plant cells (Smith et al. 1994). It has been suggested that specific conditions at the mycorrhizal interface enhance $\mathrm{P}$ efflux (Smith et al. 1994). Among them, specific signalling by the host cells in the Hartig net could enhance the P flow from the fungal cells. Interestingly, direct contact between the fungus and the plant cells is not necessary for the induction of changes in fungal partner behavior (Horan \& Chilvers 1990; Kim et al. 1999; Martin et al. 2001; Plett et al. 2011) suggesting that signalling occurred between the ectomycorrhizal fungus and its host plant before the formation of ectomycorrhizal roots. Such interactions could also impact fungal $\mathrm{P}$ metabolism and lead to $\mathrm{P}$ efflux from the fungus toward the external medium. 
In this work, we hypothesize that the host plant is able to exert specific effects on P efflux from the fungal cells through the hydrolysis of fungal polyP. We addressed this hypothesis using an in vitro system enabling the plant and the ECM fungus to interact in the same bathing solution taken as an experimental model of the symbiotic interface. We used the ECM fungus Hebeloma cylindrosporum grown in vitro to obtain mycelia enriched in longchain polyP. The mycelia were then incubated without plant or with host (Pinus pinaster) or non-host (Zea mays) plant species. Maize was considered to be representative of AM-forming plants, so this experimental design should help to assess the specificity of the effect of plants forming ECM or AM symbiosis.

The first step of our study was to determine whether two $\mathrm{P}$ conditions, without $\mathrm{P}$ or with nonlimiting $\mathrm{P}$ supply, could affect the rate of $\mathrm{P}$ accumulation and polyP formation in the hyphae of the ECM species, using ${ }^{32} \mathrm{P}$ labeling, in vitro and in vivo ${ }^{31} \mathrm{P}$ NMR and cytological staining. Our findings demonstrated that $\mathrm{P}$ application triggered a massive accumulation of $\mathrm{P}$ as newly synthesized long-chain polyP in $H$. cylindrosporum if previously grown under P-deficient conditions. We used therefore these polyP-enriched mycelia to carry out the rest of our study.

The second step was to investigate the influence of a host plant ( $P$. pinaster) or a non-host plant (Z. mays) on the fungal $\mathrm{P}$ efflux and the fate of fungal polyP during an in vitro timecourse experiment. ${ }^{32} \mathrm{P}$ labelled mycelia were used to quantify fungal $\mathrm{P}$ fluxes towards the plant compartments and the interaction medium without added $\mathrm{P}$ or carbohydrates, which was taken as a proxy for the interfacial apoplast. Also the fate of fungal $\mathrm{P}$ compounds, mostly polyP, was followed by in vivo ${ }^{31} \mathrm{P}$ NMR in unlabelled mycelia. The findings allowed a better understanding of the role of the host plant in the regulation of the fungal P metabolism at the root-fungus interface. 


\section{Material and Methods}

\section{Solutions}

Three solutions were used in this study, namely (1) a complete nutrient solution to grow the fungus, (2) a mineral solution to grow the plants and (3) an interaction medium (IM) to incubate the plants and the fungus together. The complete fungal nutrient solution was based on N6 medium described by Louche et al. (2010) and contained $6 \mathrm{mM} \mathrm{KNO}$, $4 \mathrm{mM} \mathrm{KCl,} 1$ $\mathrm{mM} \mathrm{CaCl}_{2}, 1 \mathrm{mM} \mathrm{MgSO}_{4}, 50 \mu \mathrm{g} \mathrm{l}^{-1}$ thiamine hydrochloride, $0.5 \mathrm{ml} \mathrm{l}^{-1} 1 \% \mathrm{Fe}$ citrate solution, $0.2 \mathrm{ml} \mathrm{l}^{-1}$ micronutrients of Morizet \& Mingeau (1976) solution and $55 \mathrm{mM}$ glucose, $\mathrm{pH}$ 5.5. This solution was used either without any added $\mathrm{P}$ (-P solution) or with 1 $\mathrm{mM} \mathrm{NaH}{ }_{2} \mathrm{PO}_{4}$ (instead of $3 \mathrm{mM}$ in Louche et al. 2010) (+P solution). Where indicated $+\mathrm{P}$ solution was labelled with ${ }^{32} \mathrm{P}$ orthophosphate $\left(\mathrm{KH}_{2}{ }^{32} \mathrm{PO}_{4}\right.$ in water from Amersham, France, $\mathrm{pH} 4.5)$. The radiolabelled source was diluted to obtain an initial activity of $3.310^{4} \mathrm{~Bq}$ per $\mu$ mol $\mathrm{Pi}$ in the solution. The plant mineral solution had the same $\mathrm{pH}$ and concentrations of thiamine hydrochloride, Fe citrate, micronutrients and $\mathrm{MgSO}_{4}$ as the fungal nutrient solution. It did not contain any glucose, and other salts were $0.2 \mathrm{mM} \mathrm{Ca}\left(\mathrm{NO}_{3}\right)_{2}, 0.6 \mathrm{mM} \mathrm{KNO}, 0.2$ $\mathrm{mM} \mathrm{KCl}$ and $0.2 \mathrm{mM} \mathrm{KH}_{2} \mathrm{PO}_{4}(\operatorname{Irshad}$ et al. 2011). The IM was made without any $\mathrm{P}$ or carbon source. It contained only $0.2 \mathrm{mM} \mathrm{MgSO}_{4}$ and $0.5 \mathrm{mM} \mathrm{CaCl}_{2}$ and was buffered at $\mathrm{pH}$ 5.5 with $5 \mathrm{mM}$ MES (2-N-morpholino-ethanesulfonic acid, 4-morpholineethanesulfonic acid). All these solutions were used after sterilization $\left(20 \mathrm{~min}, 121^{\circ} \mathrm{C}\right)$. Where stated radioactive ${ }^{32} \mathrm{P}$ was added to the fungal complete nutrient solution under sterile conditions.

\section{Biological material}

\section{Ectomycorrhizal fungal material}

A dikaryotic strain (D2) of the ectomycorrhizal basidiomycete Hebeloma cylindrosporum Romagnesi resulting from the plasmogamy of two compatible homokaryotic strains h1 and h7 (Debaud \& Gay 1987) was used in this study. The fungus used in all experiments originated from 3-week-old stock cultures grown in the dark at $25{ }^{\circ} \mathrm{C}$ on agar nutrient medium (N6 medium) as described by Louche et al. (2010). The mycelia were always grown in glass flasks containing $40 \mathrm{ml}$ of complete nutrient solution, without shaking (Scheromm et al. 1990) (Supporting Information Fig. S1). The fungal plug ( $8 \mathrm{~mm}$ diameter) was maintained at the surface of the medium with a nichrome wire. After 7 days in the complete nutrient solution containing $1 \mathrm{mM} \mathrm{Pi}$ the mycelia were transferred into new flasks containing the 
complete nutrient solution without added Pi (-P) or with $1 \mathrm{mM} \mathrm{Pi}(+\mathrm{P})$. Before being transferred in the $-\mathrm{P}$ solution, mycelia were rinsed several times in the nutrient solution without $\mathrm{P}$ to eliminate the carryover solution from the hyphae, as described in Fig. S1. The fungus was grown for 5 additional days to obtain P-starved or P-sufficient mycelia, respectively (Supporting Information Fig. S2). Unless stated mycelia were then transferred for $16 \mathrm{~h}$ into the complete nutrient solution containing $1 \mathrm{mM} \mathrm{Pi}$, whether labelled or not with ${ }^{32} \mathrm{P}$ (P-resupply or ${ }^{32} \mathrm{P}$-resupply period). Afterward, mycelia were suspended, using the nichrome wire, inside $60 \mathrm{ml}$ syringes equipped with a tap at their bottom and filled with 15 $\mathrm{ml}$ of IM. Each fungus was rinsed with successive withdrawn and addition of $15 \mathrm{ml}$ of IM. For all experiments except one (experiment $1,{ }^{32} \mathrm{P}$ rinsing experiment, see below), IM was renewed 5 times at 1, 15, 30, 45 and 90 min. This procedure allowed the Pi solution adhering to the fungal material to be discarded.

\section{Plant material}

The host plant was maritime pine (Pinus pinaster Soland in Ait. from the Médoc, LandesSore-VG source, France). The non-mycorrhizal seedlings were obtained from seeds surfacesterilized with $30 \%(\mathrm{w} / \mathrm{w}) \mathrm{H}_{2} \mathrm{O}_{2}$ solution for $40 \mathrm{~min}$ and soaked in sterile distilled water for $48 \mathrm{~h}$ at $4{ }^{\circ} \mathrm{C}$. Germination was performed on agar-solidified media $\left(10 \mathrm{~g} \mathrm{l}^{-1}\right)$ containing $2 \mathrm{~g}^{-1}$ glucose to reveal any contamination. Plants were grown in test tubes (Plassard et al. 1994) and watered every week with $20 \mathrm{ml}$ of mineral solution described above. After two months the mineral solution was removed and replaced by $0.2 \mathrm{mM} \mathrm{CaSO}_{4}$ sterile solution for 1 week. Finally the $\mathrm{CaSO}_{4}$ solution was removed and substituted by the IM for $24 \mathrm{~h}$ for root acclimatization to the medium. Maize (Zea mays L. var. Volga) seedlings were obtained from seeds surface-sterilized with $6 \% \mathrm{H}_{2} \mathrm{O}_{2}$ solution for $30 \mathrm{~min}$ and rinsed with sterile distilled water. Germination was carried out at $30{ }^{\circ} \mathrm{C}$ between two sterile sheets of filter paper previously wetted with deionized sterile water. After 6 days of germination plants were transferred to test tubes with $0.2 \mathrm{mM} \mathrm{CaSO}_{4}$ solution for 3 days before undergoing an acclimatization period of $24 \mathrm{~h}$ in IM. All test tubes were placed in a growth chamber under a $16 \mathrm{~h} / 8 \mathrm{~h}$ light/dark cycle at $25{ }^{\circ} \mathrm{C} / 20{ }^{\circ} \mathrm{C}, 80 \% / 100 \% \mathrm{RH}, \mathrm{CO}_{2}$ concentration of about 350 $10^{-6} \mathrm{dm}^{3} \mathrm{dm}^{-3}$ and a PAR (Photosynthetically Active Radiation) of approximately $400 \mu \mathrm{mol}$ $\mathrm{m}^{-2} \mathrm{~s}^{-1}(400-700 \mathrm{~nm})$. At the beginning of the experiment pine and maize plants had similar total biomass. 


\section{Experimental approaches}

Fate of $P$ in $H$. cylindrosporum mycelia in pure culture

Four independent experiments were carried out to follow the fate of $\mathrm{P}$ taken up by $H$. cylindrosporum mycelia during a P-resupply period according to their previous $\mathrm{P}$ status (Supporting Information Fig. S2, Table S1)

Experiment 1. P-starved and P-sufficient ${ }^{32} \mathrm{P}$ labeled mycelia (6 replicates for each condition) were transferred from the radioactive solution $\left({ }^{32} \mathrm{P}\right.$-resupply period) to $60 \mathrm{ml}$ syringes filled with $15 \mathrm{ml}$ of IM. Mycelia were rinsed about 18 times with $15 \mathrm{ml}$ of IM during $360 \mathrm{~min}$. After each rinsing period, IM was collected and substituted by fresh IM solution before being assayed for ${ }^{32} \mathrm{P}$ radioactivity. The ${ }^{32} \mathrm{P}$ remaining in the mycelia at the end of the experiment was also measured and the amount of Pi taken up by each mycelium calculated using the specific activity of phosphate in the nutrient solution.

Experiments 2 and 3. In vivo and in vitro ${ }^{31} \mathrm{P}$ NMR measurements were used to examine Pstarved $(n=6)$ and P-sufficient $(n=6)$ non-labelled mycelia sampled without or after a Presupply period (24 mycelia in total).

For in vivo ${ }^{31} \mathrm{P}$ measurements (experiment 2 ), the six mycelia were introduced into the 10mm NMR tube as described by Roby et al. (1987). Mycelia were continuously perfused with IM and aerated with a stream of pure oxygen (Lee \& Ratcliffe 1983). Acquisition conditions were: $90^{\circ}$ radio frequency pulses angle, 20 -s inter-scan delay giving a fully relaxed spectrum (Quiquampoix et al. 1993), 180 scans giving a total accumulation time of $1 \mathrm{~h}$. The probe temperature was $25^{\circ} \mathrm{C}$. Before Fourier transformation, in vivo spectra were apodized using a $10 \mathrm{~Hz}$ exponential function and zero-filled to $16 \mathrm{~K}$ points, then phased and baseline corrected. An aqueous solution of methylene diphosphonate (MDP) contained in a 1-mm capillary was centered in the inlet tube, as described by Roby et al. (1987). Peak assignments were carried out according to chemical shifts referenced to MDP at $16.38 \mathrm{ppm}$ and from spectra of perchloric extracts that contained soluble, low-molecular weight constituents (see below). Vacuolar and cytoplasmic $\mathrm{Pi}$ were distinguished because of the $\mathrm{pH}$ dependent chemical shift. For quantification the peaks of both intracellular Pi and polyP were integrated and the sum fixed to 100 to give relative values. We also integrated the peak area of polyP and Pi which were then normalized relative to that of MDP. 
For in vitro ${ }^{31} \mathrm{P}$ measurements (experiment 3 ), mycelia were fixed with liquid nitrogen and stored at $-80{ }^{\circ} \mathrm{C}$ before extraction. For each treatment six frozen mycelia were crushed together with $1 \mathrm{ml}$ of $70 \%(\mathrm{v} / \mathrm{v})$ perchloric acid. The frozen powder was then treated as described by Roby et al. (1987) to obtain a supernatant without $\mathrm{HClO}_{4}$ that was freeze-dried and stored at $-80{ }^{\circ} \mathrm{C}$ until required for NMR measurements. Perchloric acid extracts were obtained as follows: the freeze-dried material was dissolved in $1 \mathrm{ml}$ of $40 \mathrm{mM}$ MOPS (3-Nmorpholino-propansulfonic acid) buffer, $\mathrm{pH}$ 7.8, containing $60 \mathrm{mM}$ CDTA $(1,2-$ diaminocyclohexanetetraacetic acid monohydrate) and $10 \% \mathrm{D}_{2} \mathrm{O}$ (Roby et al. 1987). ${ }^{31} \mathrm{P}$ NMR spectra were recorded on a Varian UNITY INOVA $500 \mathrm{MHz}$ spectrometer operating at 202.4 MHz for ${ }^{31} \mathrm{P}$, equipped with a 10-mm broad band probe. The deuterium resonance of ${ }^{2} \mathrm{H}_{2} \mathrm{O}$ added into the extract was used as a lock signal. Spectra were acquired at $25^{\circ} \mathrm{C}$ using a $90^{\circ}$ pulse angle, a 4 -s inter-scan delay and a ${ }^{1} \mathrm{H}$ decoupling. In vitro spectra were apodized using a $2 \mathrm{~Hz}$ exponential line broadening, zero-filled to $16 \mathrm{~K}$ points then phased and baselinecorrected. A sufficient number of accumulations were used to give an acceptable signal to noise ratio. Peak assignments were established from chemical shifts of standard solutions containing known phosphorylated molecules and confirmed by direct addition of commercially available compounds.

Both experiments were repeated twice independently (Table S1). For each experiment the six replicates were pooled together to increase the signal to noise ratio and to decrease the time required to get NMR spectra of good quality after $1 \mathrm{~h} .{ }^{31} \mathrm{P}$ spectra were processed and analyzed using both VnmrJ and ACDlabs softwares.

Experiment 4. PolyP granules were examined in P-starved $(n=3)$ and P-sufficient $(n=3)$ mycelia, without or after the $16 \mathrm{~h}$ P-resupply period, for a total of 12 mycelia (Supporting Information Fig. S2). An independent experiment (denoted exp $4 *$ ) was carried out with Pstarved mycelia to assess the dependence of polyP granule formation on Pi concentration and incubation time. Those mycelia were incubated in complete nutrient solution supplied with 0.01 or $0.1 \mathrm{mM} \mathrm{NaH} \mathrm{PO}_{4}$ for 1 and $16 \mathrm{~h}$ ( 3 replicates per condition, giving 12 mycelia in total). For the observation of polyP, mycelia were placed in a solution of $95 \%$ ethanol to precipitate polyP before staining. The fungal material was stored in ethanol at $4{ }^{\circ} \mathrm{C}$ until analysis (Ashford et al. 1999).

This article is protected by copyright. All rights reserved. 


\section{Plant interaction experiment}

Experiments 5 and 6. The $60 \mathrm{ml}$ syringe, closed at the bottom by a valve and equipped at the top with a teflon tube for the supply of sterile air, was used as an in vitro experimental device to study the interaction between the fungus and the plant (Supporting information Fig. S3). Independent plant interaction experiments were carried out with P-starved mycelia using either ${ }^{32} \mathrm{P}$ labelled (experiment 5) or unlabelled $\mathrm{P}$ (experiment 6) (Fig. 1). After the $16 \mathrm{~h} \mathrm{P-}$ resupply period, mycelia were transferred from the glass flasks to the syringes filled with 15 $\mathrm{ml}$ of IM. Mycelia were rinsed 5 times for a total of $90 \mathrm{~min}$ as described above. The syringes were filled with $60 \mathrm{ml}$ of a new IM (t0) and the fungi were incubated alone (no plant) or with roots from three maize plants (with Z. mays) or three pines (with $P$. pinaster). This incubation was carried out under continuous light for up to $48 \mathrm{~h}$ and six syringes per treatment (no plant, with $Z$. mays and with $P$. pinaster) were destructively sampled after $6,24,48 \mathrm{~h}$ recorded t6, t24 and t48, respectively (Fig. 1). The total number of syringes was 54 (corresponding to 3 conditions x 3 sampling times x 6 replicated syringes). At each sampling time fresh weights of mycelia and plants and volume of IM were recorded. For the radiolabelled experiment (experiment 5), amounts of radioactivity in mycelia, plants and IM were assayed as described below. For the non-radiolabelled experiment (experiment 6), mycelia were pooled and introduced in the $10-\mathrm{mm}$ NMR tube, and in vivo ${ }^{31} \mathrm{P}$ NMR measurements were carried out using the same conditions as described above. Both experiments were repeated twice, giving 4 plant-interaction experiments in total (Table S1).

\section{Chemicals and chemical assays}

Unless stated, all chemical compounds were of analytical grade and were purchased from Sigma. Radioactivity was measured in a scintillation counter (Beckman LS5801). ${ }^{32} \mathrm{P}$ released from the fungal material was measured using the Cerenkov effect by mixing $1 \mathrm{ml}$ of IM with $4 \mathrm{ml}$ of demineralised water in a scintillation vial. For solid samples, $5 \mathrm{ml}$ of scintillation liquid were added to the vial to increase the radioactivity counting efficiency. The ratio of counting efficiencies in water and scintillation liquid was measured by comparing counts for the replicate samples in either water or scintillation liquid. Data were corrected for decay and the efficiency ratio obtained was then used in calculations to normalize all radioactivity measurements.

This article is protected by copyright. All rights reserved. 
For observation of polyP granules, mycelia were rinsed with distilled water before staining with Toluidine Blue O (Ref T3260, from Sigma) as described by Ashford et al. (1999). Three fungal pieces per mycelium were mounted with water and observed under an optical microscope (Olympus BX 61). Images were taken with a Color View II® camera using Analysis@ software (Soft Imaging System, Munster, Germany). Images were analysed using ImageJ (http://imagej.nih.gov/ij/) software to determine the number of metachromatic granules in individual hyphae ( $\mathrm{n}=12$ per treatment).

\section{Statistical treatment}

Excepted for ${ }^{31} \mathrm{P}$ NMR measurements, all other results are given as means calculated from 6 $\left({ }^{32} \mathrm{P}\right.$ labelling experiments) to 12 (image analysis for polyP granules) measurements and SEM. The differences between means were analysed by one-way ANOVA followed by Tukey's HSD post-hoc test using Statistica 7.1 (StatSoft Inc., Tulsa, OK, USA). Normality was tested using the Kolmogorov Smirnov test and, where necessary, the data was either square root or $\log 10$ transformed prior to analysis to meet the assumptions of ANOVA. For

${ }^{31} \mathrm{P}$ NMR measurements, data in percentage were transformed $(\arcsin { } \mathrm{x})$ as described in Legendre \& Legendre (1998) before ANOVA.

\section{Results}

\section{Effect of P-resupply on $\mathbf{P}$ accumulation in $\mathrm{H}$. cylindrosporum hyphae using ${ }^{32} \mathrm{P}$ and ${ }^{31} \mathrm{P}$ NMR}

Figure $2 \mathrm{a}$ shows the amounts of ${ }^{32} \mathrm{P}$ measured in the IM of P-starved and P-sufficient $H$. cylindrosporum mycelia after P-resupply period with the ${ }^{32} \mathrm{P}$ tracer (experiment 1, Fig. S2). The amounts of radioactivity were measured over 6-h rinsing experiments. Whatever the $\mathrm{P}$ status of the mycelia, they released huge amounts of radioactivity during the first 40 minutes of rinsing, suggesting important nonspecific binding of the tracer at the surface of the fungal cells. Thereafter, only small increases in the amount of ${ }^{32} \mathrm{P}$ were measured in the IM either in P-starved or P-sufficient mycelia. These findings indicate that about 40 minutes were required for the complete removal of unbound ${ }^{32} \mathrm{P}$ from free space and cell walls. At the end of the rinsing period, the total amounts of ${ }^{32} \mathrm{P}$ released in IM by P-starved and P-sufficient mycelia were not significantly different (Fig. 2a). In contrast, ${ }^{32} \mathrm{P}$ values remaining in $\mathrm{P}$ starved and P-sufficient mycelia at the end of the rinsing period were markedly different (Fig. $2 b$ ). The corresponding values of $\mathrm{P}$ accumulation calculated using ${ }^{32} \mathrm{P}$ phosphate specific 
activity in the culture medium were also different with $3.6 \pm 0.7$ and $0.8 \pm 0.2 \mu \mathrm{mol} \mathrm{g}^{-1}$ fungal FW in P-starved and P-sufficient mycelia, respectively. These data indicated that P-starved mycelia accumulated four times more $\mathrm{P}$ than $\mathrm{P}$-sufficient mycelia during their exposure to the P-resupply period.

Figure 3 shows in vivo ${ }^{31} \mathrm{P}$ NMR spectra from P-starved and P-sufficient mycelia without Presupply (experiment 2, Fig. S2). Signal identification was carried out according to chemical shifts reported in other ectomycorrhizal fungi (Gerlitz \& Werk 1994; Martins et al. 1999). We also used the spectra of $H$. cylindrosporum perchloric extracts obtained from P-starved and P-sufficient mycelia without and after P-resupply (experiment 3, Supporting Information Fig. S4). The in vivo NMR spectra of $\mathrm{P}$-starved and $\mathrm{P}$-sufficient mycelia exhibited same ${ }^{31} \mathrm{P}$ resonance signals. The first three signals visible in all spectra were assigned to cytoplasmic Pi (peak b, 1.6 ppm), vacuolar Pi (peak c, 0.4 ppm) and to glycerophosphocholine (peak d, 0.05 $\mathrm{ppm})$. Peaks e $(-11 \mathrm{ppm})$ and $\mathrm{f}(-13 \mathrm{ppm})$ were attributed to $\mathrm{P}$ groups of UDP-N-acetlylglucosamine. The last peak ( $\mathrm{g}$ ) at $-22 \mathrm{ppm}$ corresponded to the central Pi residues of NMRvisible polyP chain (Martin et al. 1983). Vacuolar Pi represented the major part of NMRvisible P. As shown in Table 1, the sum of cytoplasmic and vacuolar Pi represented always a great proportion of intracellular $\mathrm{P}$ with a value of about $87 \%$. In contrast, the proportion of NMR-detectable polyP was very low, whatever the P pre-treatment applied to the mycelia. The polyP fraction reached a maximum of $14 \%$ of internal Pi in P-starved mycelia. When the external Pi was increased, the polyP content slightly decreased to 10 and $7 \%$ of the total internal Pi in P-starved and P-sufficient mycelia, respectively. The 6-h rinsing period did not change the proportion of NMR-visible polyP in P-starved and P-sufficient mycelia (data not shown).

\section{Effect of P-resupply on the $\mathbf{P}$ pool in $H$. cylindrosporum hyphae observed by cytological staining}

Figure 4 shows the accumulation of metachromatic granules in P-starved and P-sufficient $H$. cylindrosporum hyphae, without and after a P-resupply period of $16 \mathrm{~h}$ (experiment 4, Fig. S2). Without P-resupply it was not possible to detect any metachromatic granules in Pstarved mycelia whereas P-sufficient mycelia contained numerous granules in their hyphae. Exposure to P-resupply led to the formation of polyP granules in previously P-starved mycelia to reach the number measured in P-sufficient mycelia. In contrast, the density of polyP granules in P-sufficient mycelia was not significantly modified after P-resupply (Fig. 
4). In a parallel experiment (experiment $4^{*}$, Fig. S2), we studied time and P concentration dependence of polyP granules formation during P-resupply by incubating P-starved mycelia for 1 and $16 \mathrm{~h}$ in a nutrient solution containing concentrations of $\mathrm{NaH}_{2} \mathrm{PO}_{4}$ of 0.01 or $0.1 \mathrm{mM}$ instead of $1 \mathrm{mM}$. Table 2 shows that $H$. cylindrosporum hyphae began to accumulate de novo synthesized metachromatic after only one hour of P-resupply. Thereafter, granule densities were not significantly different between $\mathrm{P}$ concentrations. Increasing incubation time up to 16 $\mathrm{h}$ lead to significantly higher densities of granules measured in hyphae, whatever the Pi concentration supplied to the nutrient solution. Interestingly, the densities of polyP granules observed at low Pi concentrations (such as $0.01 \mathrm{mM}$ ) were very close to those observed when $\mathrm{Pi}$ is supplied at $1 \mathrm{mM}$ (compare Fig. 4 and Table 2). Therefore, P-starved mycelia were able to synthesize de novo a large amount of total polyP during P-resupply, even at very low Pi concentrations.

\section{The impact of $P$. pinaster and $Z$. mays on ${ }^{32} \mathrm{P}$ release from $H$. cylindrosporum mycelia}

The effect of a host or a non-host plant on $\mathrm{P}$ fluxes from $H$. cylindrosporum mycelia was investigated using the ability of P-starved mycelia to accumulate a massive amount of $\mathrm{P}$ as polyP after the resupply of $\mathrm{P}$. Figure 5 shows the amounts of ${ }^{32} \mathrm{P}$ released by $H$. cylindrosporum incubated alone (no plant) or with Z. mays or P. pinaster (experiment 5, Fig. 1) and measured in plants or in the IM. For both plant species accumulated ${ }^{32} \mathrm{P}$ increased continuously with incubation time (Fig. 5, upper part). Measurements of ${ }^{32} \mathrm{P}$ in the IM showed that the fungus incubated alone (no plant) released low amounts of ${ }^{32} \mathrm{P}$ that did not increase continuously over time (Fig. 5, lower part). In contrast to ${ }^{32} \mathrm{P}$ accumulation in plant tissues, the amounts and the patterns of ${ }^{32} \mathrm{P}$ release in IM when plants are interacting with the fungus were markedly different between the two plant species. With the non-host plant $(Z$. mays), the amounts of ${ }^{32} \mathrm{P}$ were first smaller $(6 \mathrm{~h})$, not different $(24 \mathrm{~h})$ and higher $(48 \mathrm{~h})$ than those measured with no plant. Considering the whole duration of incubation, the ${ }^{32} \mathrm{P}$ release by $H$. cylindrosporum mycelia interacting with $Z$. mays increased slightly with time but remained low after $48 \mathrm{~h}$ (91 Bq g ${ }^{-1}$ fungal $\mathrm{FW}$ ) (Fig. 5, lower part). Thus, most of fungal ${ }^{32} \mathrm{P}$ released (about $75 \%$ ) was accumulated in maize plants. By comparison, the amounts of fungal ${ }^{32} \mathrm{P}$ released into the IM resulting from the co-incubation with the host plant $(P$. pinaster) were much greater than the values measured with no plant after 24 and $48 \mathrm{~h}$ of interaction. In $P$. pinaster treatments, fungal ${ }^{32} \mathrm{P}$ in IM increased regularly with interaction time to reach about $348 \mathrm{~Bq} \mathrm{~g}^{-1}$ fungal $\mathrm{FW}$ at $48 \mathrm{~h}$, representing approximately half of total ${ }^{32} \mathrm{P}$ released by the fungus incubated with $P$. pinaster (Fig. 5). Finally, as shown in 
supplementary Table $\mathrm{S} 2$, the total amount of ${ }^{32} \mathrm{P}$ released by $H$. cylindrosporum increased with Z. mays and P. pinaster, indicating that $\mathrm{P}$ efflux was stimulated by the presence of plants. More remarkably, when the fungus was incubated with its host plant $P$. pinaster fungal release of ${ }^{32} \mathrm{P}$ was enhanced two-fold compared to Z. mays treatments (Table S2). The total amount of ${ }^{32} \mathrm{P}$ released by the fungus corresponded to $0.35 \%, 5.3 \%$ and $9.6 \%$ of initial radioactivity for no plant, with $Z$. mays and with $P$. pinaster after $48 \mathrm{~h}$, respectively.

\section{The impact of $P$. pinaster and $Z$. mays roots in vitro on ${ }^{31} \mathrm{P}$ NMR-visible polyP in $H$. cylindrosporum mycelia}

Figure 6 shows in vivo ${ }^{31} \mathrm{P}$ NMR spectra of $H$. cylindrosporum $\mathrm{P}$-starved mycelia re-supplied with ${ }^{31} \mathrm{P}$ and then incubated over $48 \mathrm{~h}$ without seedlings (no plant) or with $Z$. mays or $P$. pinaster (experiment 6, Fig. 1). Peak identification was carried out according to chemical shifts and from spectra of perchloric extracts (Supporting Information Fig. S4). The four expected signals for $\mathrm{P}$ metabolites that are cytosolic and vacuolar $\mathrm{Pi}$, UDP-N-acetylglucosamine and central polyP (Fig. 3), were present in the spectra of $H$. cylindrosporum mycelia either incubated alone (no plant) or with plants (Z. mays and P. pinaster) (Fig. 6). However, the peak attributed to glycerophosphocholine $(0.05 \mathrm{ppm})$ in P-starved and Psufficient mycelia (Fig. 3) was observed in no plant-spectra but disappeared from Z. mays and P. pinaster-spectra (Fig. 6). Considering the whole duration of experiment, the most obvious changes in ${ }^{31} \mathrm{P}$ NMR spectra involved mainly central polyP and intracellular (cytoplasmic and vacuolar) Pi pools. The changes in relative central polyP and Pi contents, estimated as the intensity ratio of these signals, were first integrated in spectra from each condition and incubation period and are given in Table $3 \mathrm{a}$.

In agreement with our previous results (see Table 1), the proportion of NMR-visible central polyP chains in no plant-mycelia was low, ranging from 7 to $9 \%$. When incubated with maize seedlings, Z. mays-mycelia contained also a small proportion of polyP, ranging from 6 to $10 \%$. By contrast, in $P$. pinaster-mycelia NMR-detectable polyP proportion was increased up to between 24 and $26 \%$.. This increase was constant over the 48 h-period (Table $3 \mathrm{a}$ ). When the values were averaged over the whole incubation period, the proportion of NMRdetectable polyP in $P$. pinaster-mycelia was significantly increased compared to no plantand Z. mays-mycelia. This increase corresponded to a decrease in the proportions of Pi (Table 3a). As the same reference (MDP) was used in all the NMR experiments, we also integrated the peak area of polyP and Pi relative to that of MDP arbitrarily fixed to 1 (Table $3 b$ ). When

This article is protected by copyright. All rights reserved. 
averaged over the whole incubation period, only the polyP fraction in $P$. pinaster-mycelia was significantly higher than the means calculated in no plant- and Z. mays-mycelia whereas the Pi fractions were not significantly different among the three treatments (Table $3 b$ ).

\section{Discussion}

\section{$P$ starvation and increased fungal accumulation of $P$ : what is the role of polyP?}

The labelling experiment carried out with $H$. cylindrosporum mycelia grown in pure culture showed clearly that $\mathrm{P}$ starvation had a major impact on the subsequent accumulation of $\mathrm{P}$ by the fungal cells. P-starved mycelia accumulated about 4 times more $\mathrm{P}$ than $\mathrm{P}$-sufficient mycelia when measured after the rinsing period. The over-accumulation of $\mathrm{P}$ by P-starved microbial cells has previously been reported and attributed to the capacity for synthesizing molecules of polyP through the "polyP overplus" (see Harold 1966). As "polyP overplus" has been demonstrated in yeast (Harold 1966; Trilisenko et al. 2002) and in AM fungi (Ezawa et al. 2004; Hijikata et al. 2010; Kikuchi et al. 2014), one should expect its occurrence in ECM fungi. Surprisingly, our results showed that the relative contribution of in vivo ${ }^{31} \mathrm{P}$ NMRvisible polyP over total inorganic $\mathrm{P}$ did not vary with $\mathrm{P}$-status of mycelia without and after Presupply. In contrast, dye application revealed the presence of metachromatic granules synthesized by P-starved fungal cells during the P-resupply period and this de novo synthesis of polyP could explain the difference of ${ }^{32} \mathrm{P}$ accumulation observed in P-starved and Psufficient mycelia. Our results are in agreement with those obtained by Lapeyrie et al. (1984) who showed that the ECM fungus $P$. involutus did not contain any metachromatic granules after P-starvation and abundant populations of granules after the transfer of these P-starved mycelia in $\mathrm{P}$ containing solution. The discrepancy between the results obtained with in vivo

${ }^{31} \mathrm{P}$ NMR and dye application may be explained if the mechanism of polyP synthesis in ECM fungi is similar to that described in yeast (Langen et al. 1962, cited in Harold 1966). Using differential extraction, four distinct polyP fractions were identified in yeast, whose average length were 260 (fraction 4), 55 (fraction 3), 20 (fraction 2) and 4 (fraction 1) Pi residues. Using radiolabelled $\mathrm{P}$ supply, it was shown that ${ }^{32} \mathrm{P}$ was most rapidly incorporated into the high molecular weight fraction 4, whereas incorporation into other fractions was slower (Langen et al. 1962, cited in Harold 1966). In addition, the same authors demonstrated that $\mathrm{P}$ starvation increased the rate of polyP synthesis. Therefore, our results could be explained by a preferential incorporation of the newly absorbed $\mathrm{Pi}$ in starved cells in long-chain poly $\mathrm{P}$ of high molecular weight that are not visible using in vivo ${ }^{31} \mathrm{P}$ NMR because they are not freely

This article is protected by copyright. All rights reserved. 
mobile. The chain length of these polyPs could be greater than $200 \mathrm{Pi}$ residues as measured in yeast (Vagabov et al. 2008) or AM fungi (Ezawa et al. 2004). The size of ${ }^{31} \mathrm{P}$ NMR visible polyP can be calculated if the peak corresponding to the resonance of the end or the penultimate phosphates is higher than the signal-to-noise ratio. In H. cylindrosporum, such calculation can be made only using in vitro spectra, giving a chain length around $10 \mathrm{Pi}$ residues. In contrast, in vivo spectra displayed only internal $\mathrm{P}$ of polyP, suggesting that they are longer than $10 \mathrm{Pi}$ residues. The same situation was observed in spectra from $C$. graniforme by Martin et al. (1985). These authors estimated the minimal chain length of polyP in vivo to be not less than $30 \mathrm{P}$ residues. Our results suggest that $H$. cylindrosporum may contain at least two pools of polyP, the first comprised of rather long-chain polyP not visible by in vivo ${ }^{31} \mathrm{P}$ NMR that is specifically increased by P-resupply in P-starved fungal cells and the second comprised of polyP of short-chain that could be around $30 \mathrm{Pi}$ residues long in living mycelia that is relatively stable and did not seem to depend on $\mathrm{P}$ status of fungal cells.

External Pi concentration can also affect the rate of polyP accumulation. In our study we supplied $1 \mathrm{mM}$ Pi during the P-resupply, an extremely high concentration when compared with $\mathrm{Pi}$ concentration in soil solution, which is usually considered to be in the range 1-10 $\mu \mathrm{M}$ (reviewed by Hinsinger 2001). However our results showed that the synthesis of new polyP revealed by cytochemistry was not restricted to this high $\mathrm{P}$ supply (1 $\mathrm{mM})$ since metachromatic granules were detected after exposure to Pi concentrations as low as $0.01 \mathrm{mM}$. Our results are comparable to those reported in P. involutus P-starved mycelia which also started to accumulate metachromatic granules in solutions as dilute as $0.005 \mathrm{mM} \mathrm{Pi}$ (Lapeyrie et al. 1984). However, these authors reported that at least 4 hours were required to observe granules in $P$. involutus hyphae whereas one hour of incubation was sufficient for $H$. cylindrosporum. These differences could be explained by the use of older biological material and by the radial cutting of the mycelia leading to cellular damage in the case of experiments done with $P$. involutus. Taken together, these results strongly suggest that polyP synthesis operates in P-starved ECM species such as $H$. cylindrosporum and P. involutus at external $\mathrm{P}$ concentrations similar to those that can be found in the soil solution that are in the micromolar range. Such ability to synthesize new polyP by P-starved fungal cells would increase the capacity of the fungus to exploit patches of $\mathrm{P}$ rich soil that can be found in natural conditions. 


\section{The host plant $P$. pinaster enhanced ${ }^{32} \mathrm{P}$ efflux from $H$. cylindrosporum mycelia}

Calculated over the whole period of incubation (48 h), H. cylindrosporum hyphae released a very low proportion (on average $0.35 \%$ ) of the ${ }^{32} \mathrm{P}$ accumulated during the P-resupply period when incubated alone in the IM. This value is much lower than those measured in three ECM species (P. tinctorius, P. involutus and H. crustuliniforme) by Cairney \& Smith (1993a). These authors found a release of ${ }^{32} \mathrm{P}$ ranging from 7 to $11 \%$ of absorbed ${ }^{32} \mathrm{P}$ when rinsed mycelia were transferred for $8 \mathrm{~h}$ in distilled water. Depending on the fungal species, these values were multiplied by 2 or 3 by the presence of external $\mathrm{KCl}$ supplied at $20 \mathrm{mM}$ compared to $\mathrm{KCl} 0.35 \mathrm{mM}$ (Cairney \& Smith 1993b). These authors found also that the addition of divalent cations such as $\mathrm{Ca}^{2+}\left(\mathrm{CaCl}_{2} 1 \mathrm{mM}\right)$ decreased five times this $\mathrm{KCl}$ enhanced ${ }^{32} \mathrm{P}$ efflux from the mycelia of $P$. tinctorius whereas $\mathrm{Mg}^{2+}\left(\mathrm{MgCl}_{2} 1 \mathrm{mM}\right)$ had no effect (Cairney \& Smith 1993b). The IM used in the present study contained no $\mathrm{KCl}$ and 0.5 $\mathrm{mM} \mathrm{CaCl} 2$ and these ionic conditions may therefore explain the low rate of ${ }^{32} \mathrm{P}$ efflux from the mycelium incubated alone. The low proportion of ${ }^{32} \mathrm{P}$ absorbed by the mycelia and lost by the fungal cells incubated without plants also indicates that our experimental system was not stressful for the fungal cells, making it suitable to study the effect of the plant on fungal ${ }^{32} \mathrm{P}$ loss and P metabolism.

In contrast to the results obtained with the fungus incubated alone, the presence of plants dramatically increased total ${ }^{32} \mathrm{P}$ efflux from the fungus by a factor 15 and 25 for maize and pine plants, respectively, after $48 \mathrm{~h}$ of incubation. At a first glance, the $\mathrm{P}$ efflux appeared not to be ECM host plant specific, because roots of the non-host plant $Z$. mays could also induce efflux. Remarkably, the IM bathing maize roots contained much less ${ }^{32} \mathrm{P}$ than pine roots, suggesting that maize roots were able to take up ${ }^{32} \mathrm{P}$ as soon as it is released by the fungus. Such an immediate absorption by maize roots would maintain a concentration gradient between intracellular $\mathrm{P}$ concentration in fungal cell and the external medium. This gradient would maximize $\mathrm{P}$ efflux and permit a net movement of $\mathrm{P}$ to the plant (Cairney \& Smith 1993a). In contrast, the ${ }^{32} \mathrm{P}$ efflux caused by the host plant $P$. pinaster was two times greater than that measured for Z. mays. Therefore, at least a part of the $\mathrm{P}$ efflux from $H$. cylindrosporum mycelia was closely related to the presence of host plant roots. More significantly, pine roots appeared to increase strongly the ${ }^{32} \mathrm{P}$ release into the IM, while the accumulation of ${ }^{32} \mathrm{P}$ by $Z$. mays and $P$. pinaster was similar suggesting that the $\mathrm{P}$ efflux exceeded even the instant requirements of pine. Such an accumulation of ${ }^{32} \mathrm{P}$ in the IM is less in favor of a passive release of $\mathrm{P}$ from the mycelium. These results suggest a host plant 
specific efflux of ${ }^{32} \mathrm{P}$ independently or in addition of a gradient between the fungus and the external medium containing the plant.

\section{PolyP metabolism of $\boldsymbol{H}$. cylindrosporum mycelia was specifically modulated by $P$. pinaster to mobilise the $\mathrm{P}$ pool for enhanced $\mathrm{P}$ efflux}

In our experiment, it was not possible to calculate the absolute size of polyP and Pi pools in the mycelia. However, the variation of peak area normalized against the reference signal (MDP) in the spectra reflects the changes in the size of polyP and Pi pools. The values showed that the signals of polyP in P. pinaster-mycelia were on average 3.6 times higher than those found in no plant- or Z. mays-mycelia (Table 3b). This supports the hypothesis that the relative changes of polyP and Pi percentages (Table 3a) are due to an increase of shortchain polyP and not to a decrease of the vacuolar Pi pool in P. pinaster-mycelia. In addition, the proportions of polyP and $\mathrm{Pi}(\mathrm{in} \%$ ) in each plant treatment were constant from 6 to $48 \mathrm{~h}$, indicating that a controlled polyP/Pi homeostasis occurs in the vacuole. Therefore, the maintenance of this homeostasis in the vacuole of mycelia incubated with $P$. pinaster, together with a continuous Pi efflux, could be mainly explained by the enhanced hydrolysis of long-chain polyP into NMR visible short-chain polyP.

Therefore, only the host plant $P$. pinaster was able to specifically enhance polyP hydrolysis in H. cylindrosporum mycelia. Grellier et al. (1989) also found that the amounts of polyP in the fungal cells from ectomycorrhizal roots of P. involutus associated with Betula pendula were higher than those detected in pure cultures of this fungus. More significantly, the proportions of NMR-detectable polyP calculated in our experiments for P. pinaster-mycelia are comparable with the values reported in excised ectomycorrhizas of this association, which ranged from 10 to $40 \%$ (Grellier et al. 1989). The appearance of NMR-visible polyP, assumed to be short-chain polyP, in $P$. pinaster-mycelia could be explained by the following sequence of events. The first step would be the release by pine roots of a signal able to elicit a specific response targeting the fungal polyP metabolism, although the nature of this signal has not yet been elucidated (Garcia et al. 2015). The signal appears to be specific of ECM plants as we did not observe the same response with maize plants. Then the second step would be to increase the activity of endopolyphosphatases acting on long-chain polyP previously synthesized during the P-resupply period and resulting in the appearance of shortchain polyP. This hypothesis is supported by the observations reported in AM plants showing that AM roots of Gigaspora margarita contained a greater amount of short-chain polyP than 
did the extraradical hyphae (Solaiman et al. 1999). These authors proposed that long-chain polyP might be partly hydrolyzed into shorter chains by endopolyphosphatase and further hydrolyzed with exopolyphosphatase to release Pi. The third step would be to increase the activity of exopolyphosphatases, as proposed by Solaiman et al. (1999), acting on short-chain polyP resulting in the production of free $\mathrm{Pi}$, which can then be released in the IM representing the apoplast of ECM. Such enzyme activities involved in polyP hydrolysis have been measured in arbuscular mycorrhizal symbiosis (Ezawa et al. 2002) but have not yet been determined in ECM fungi.

In conclusion, the combination of all the results from the different approaches used in this work lead us to propose a schematic representation regarding the fate of Pi taken up by the fungal cells and its subsequent transfer to a non-host or host-plant (Fig. 7). During Presupply, P-starved mycelia accumulated preferentially newly absorbed Pi in long-chain polyP. When the mycelia are incubated alone or with non-host plant, this pool of long-chain polyP was only marginally hydrolyzed, suggesting that the pool of free Pi was the main source of Pi released into the IM. In contrast, when the mycelia are incubated with host-plant, the pool of long-chain polyP is hydrolyzed to increase the pool of short-chain polyP, which is then hydrolyzed to supply the free Pi pool and the efflux of Pi in the IM. The activation of the polyP hydrolysis to sustain Pi efflux from the fungal cells is probably under the dependence of a specific signal released by the roots of the host-plant. This signal appears to be strictly specific of an ECM-forming plant as an AM-forming plant was not able to activate the polyP hydrolysis of $H$. cylindrosporum. Taken as a whole, our results suggest that the synthesis and transport of long-chain polyP and their subsequent hydrolysis in ECM might sustain fungal Pi release into the apoplast of Hartig net. They demonstrate also the usefulness of our simple experimental device that could be used in further studies aiming at elucidating the molecular mechanisms involved in P transfer from the fungus to the host during the ECM association.

\section{Acknowledgements}

The authors thank Kevin Garcia and Sabine D. Zimmermann for critical reading of the manuscript and Jean Trap for his advice on statistical analysis. The authors thank also the three anonymous reviewers whose constructive comments and suggestions on earlier versions of the manuscript greatly helped us to improve the manuscript. 


\section{References}

Ashford A.E., Peterson R.L., Dwarte D., \& Chilvers G.A. (1986) Polyphosphate granules in eucalypt mycorrhizas: determination by energy dispersive X-ray microanalysis. Canadian Journal of Botany 64, 677-687.

Ashford A.E., Ryde S. \& Barrow K.D. (1994) Demonstration of a short chain polyphosphate in Pisolithus tinctorius and the implications for phosphorus transport. New Phytologist $126,239-247$.

Ashford A.E., Vesk P.A., Orlovich, D.A., Markovina A.L. \& Allaway W.G. (1999) Dispersed polyphosphate in fungal vacuoles in Eucalyptus pilularis/Pisolithus tinctorius ectomycorrhizas. Fungal Genetics and Biology 28, 21-33.

Ashford A.E. \& Allaway W.G. (2002) The role of the motile tubular vacuole system in mycorrhizal fungi. Plant and Soil 244, 177-187.

Bücking H. \& Heyser W. (1999) Elemental composition and function of polyphosphates in ectomycorrhizal fungi - an X-ray microanalytical study. Mycological Research 103, 3139.

Bücking H. \& Heyser W. (2000) Subcellular compartmentation of elements in nonmycorrhizal and mycorrhizal roots of Pinus sylvestris: an X-ray microanalytical study. I. The distribution of phosphate. New Phytologist 145, 311-320.

Cairney J.W.G. \& Smith S.E. (1993a) Efflux of phosphate from the ectomycorrhizal basidiomycete Pisolithus tinctorius: general characteristics and the influence of intracellular phosphorus concentration. Mycological Research 97, 1261-1266.

Cairney J.W.G. \& Smith S.E. (1993b) The influence of monovalent cations on efflux of phosphate from the ectomycorrhizal basidiomycete Pisolithus tinctorius. Mycological Research 97, 1267-1271.

Cairney J.W.G. (2011) Ectomycorrhizal fungi: the symbiotic route to the root for phosphorus in forest soils. Plant and Soil 344, 51-71.

Chen K.Y. (1999) Study of polyphosphate metabolism in intact cells by ${ }^{31}$-P Magnetic Resonance Spectroscopy. In Progress in Molecular and Subcellular Biology, Vol. 23 (eds. H. C. Schröder \& W. E. G. Müller), pp. 253-273. Academic Press, Springer-Verlag Berlin Heidelberg.

Chilvers G.A., Lapeyrie F.F. \& Douglass P.A. (1985) A contrast between oomycetes and other taxa of mycelial fungi in regard to metachromatic granule formation. New Phytologist 99, 203-210. 
Darrah P.R., Tlalka M., Ashford A., Watkinson S.C. \& Fricker M.D. (2006) The vacuole system is a significant intracellular pathway for longitudinal solute transport in basidiomycete Fungi. Eukaryotic Cell 5, 1111-1125.

Debaud J.C. \& Gay G. (1987) In vitro fruiting under controlled conditions of the ectomycorrhizal fungus Hebeloma cylindrosporum associated with Pinus pinaster. New Phytologist 105, 429-435.

Ezawa T., Smith S.E. \& Smith F.A. (2002) P metabolism and transport in AM fungi. Plant and Soil 224, 221-230.

Ezawa T., Cavagnaro T.R., Smith S.E., Smith F.A. \& Ohtomo R. (2004) Rapid accumulation of polyphosphate in extraradical hyphae of an arbuscular mycorrhizal fungus as revealed by histochemistry and a polyphosphate kinase/luciferase system. New Phytologist 161, $387-392$.

Garcia K., Delaux P.-M., Cope K. \& Anné J.-M. (2015). Molecular signals required for the establishment and maintenance of ectomycorrhizal symbioses. New Phytologist 208, 79 87.

Gerlitz T.G.M. \& Werk W.B. (1994) Investigations on phosphate uptake and polyphosphate metabolism by mycorrhized and non-mycorrhized roots of beech and pine as investigated by in vivo ${ }^{31} \mathrm{P}-\mathrm{NMR}$. Mycorrhiza 4, 207-214.

Grellier B., Strullu D.G., Martin F. \& Renaudin S. (1989) Synthesis in vivo, microanalysis and ${ }^{31}$ P-NMR study of metachromatic granules in birch mycorrhizas. New Phytologist $112,49-54$.

Harrison M.J., Dewbre G.R. \& Liu J. (2002) A phosphate transporter from Medicago truncatula involved in the acquisition of phosphate released by arbuscular mycorrhizal fungi. The Plant Cell 14, 2413-2429.

Harold F.M. (1966) Inorganic polyphosphates in biology: Structure, metabolism and function. Bacteriological Reviews 30, 772-794.

Hijikata N., Murase M., Tani C., Ohtomo R., Mitsuru O. \& Ezawa T. (2010) Polyphosphate has a central role in the rapid and massive accumulation of phosphorus in extraradical mycelium of an arbuscular mycorrhizal fungus. New Phytologist 186, 285-289.

Hinsinger P. (2001) Bioavailability of soil inorganic P in the rhizosphere as affected by rootinduced chemical changes: a review. Plant and Soil 237, 173-195.

Horan D.P. \& Chilvers G.A. (1990) Chemotropism-the key to ectomycorrhiza formation. New Phytologist 116, 297-301. 
Irshad U., Villenave C., Brauman A. \& Plassard C. (2011) Grazing by nematodes on rhizosphere bacteria enhances nitrate and phosphorus availability to Pinus pinaster seedlings. Soil Biology and Biochemistry 43, 2121-2126.

Kariman K., Barker S.J., Jost R., Finnegan P.M. \& Tibbett M. (2014) A novel plant-fungus symbiosis benefits the host without forming mycorrhizal structures. New Phytologist 201, 1413-1422.

Kikuchi Y., Hijikata N., Yokoyama K., Ohtomo R., Handa Y., Kawaguchi M., ..,, Ezawa T. (2014) Polyphosphate accumulation is driven by transcriptome alterations that lead to near-synchronous and near-equivalent uptake of inorganic cations in an arbuscular mycorrhizal fungus. New Phytologist 204, 638-649.

Kim S.J., Hiremath S.T. \& Podila G.K. (1999) Cloning and identification of symbiosisregulated genes from the ectomycorrhizal Laccaria bicolor. Mycological Research 103, 168-172.

Lapeyrie F.F., Chilvers G.A. \& Douglass P.A. (1984) Formation of metachromatic granules following phosphate uptake by mycelial hyphae of an ectomycorrhizal fungus. New Phytologist 98, 345-360.

Lee R.B. \& Ratcliffe R.G. (1983) Development of an aeration system for use in plant tissue NMR experiments. Journal of Experimental Botany 34, 1213-1221.

Legendre P. \& Legendre L. (1998) Complex ecological data sets. In Numerical Ecology, 2nd edition, pp. 33-46. Elsevier Science B.V., Amsterdam.

Loth-Pereda V., Orsini E., Courty P.-E., Lota F., Kohler A., Diss L., ..., Martin F. (2011) Structure and expression profile of the phosphate Pht1 transporter gene family in mycorrhizal Populus trichocarpa. Plant Physiology 156, 2141-2154.

Louche J., Ali M.A., Cloutier-Hurteau B., Sauvage F.-X., Quiquampoix H. \& Plassard C. (2010) Efficiency of acid phosphatases secreted from the ectomycorrhizal fungus Hebeloma cylindrosporum to hydrolyse organic phosphorus in podzols. FEMS Microbiology and Ecology 73, 323-335.

Martin F., Canet D., Rolin D., Marchal J.P. \& Larher F. (1983) Phosphorus-31 nuclear magnetic resonance study of polyphosphate metabolism in intact ectomycorrhizal fungi. Plant and Soil 71, 469-476.

Martin F., Marchal J.-P., Timinska A. \& Canet D. (1985) The metabolism and physical state of polyphosphate in ectomycorrhizal fungi. $\mathrm{A}^{31} \mathrm{P}$ nuclear magnetic resonance study. New Phytologist 101, 275-290. 
Martin F., Duplessis S., Ditengou F., Lagrange H., Voiblet C. \& Lapeyrie F. (2001) Developmental cross talking in the ectomycorrhizal symbiosis: signals and communication genes. New Phytologist 151, 145-154.

Martins A., Santos M., Santos H. \& Pais M.S. (1999) A ${ }^{31}$ P nuclear magnetic resonance study of phosphate levels in roots of ectomycorrhizal and nonmycorrhizal plants of Castanea sativa Mill. Trees 13, 168-172.

Melin E. \& Nilsson H. (1950) Transfer of radioactive phosphorus to pine seedlings by means of mycorrhizal hyphae. Physiologia Plantarum 3, 88-92.

Morizet J. \& Mingeau M. (1976) Influence des facteurs du milieu sur l'absorption hydrique (étude effectuée sur Tomate décapitée en exsudation).I. Facteurs nutritionnels. Annales Agronomiques 27, 183-205.

Peterson R.L. \& Bonfante P. (1994) Comparative structure of vesicular-arbuscular mycorrhizas and ectomycorrhizas. Plant and Soil 159, 79-88.

Pfeffer P.E., Bago B. \& Shachar-Hill Y. (2001) Exploring mycorrhizal function with NMR spectroscopy. New Phytologist 150, 543-553.

Plassard C., Barry D., Eltrop L. \& Mousain D. (1994) Nitrate uptake in maritime pine (Pinus pinaster) and the ectomycorrhizal fungus Hebeloma cylindrosporum: effect of ectomycorrhizal symbiosis. Canadian Journal of Botany 72, 189-197.

Plassard C. \& Dell B. (2010) Phosphorus nutrition of mycorrhizal trees. Tree Physiology 30, 1129-1139.

Plett J.M., Kemppainen M., Kale S.D., Kohler A., Legué V., Brun A., ..., Martin F. (2011) A secreted effector protein of Laccaria bicolor is required for symbiosis development. Current Biology 21, 1197-1203.

Quiquampoix H., Bačić G., Loughman B.C. \& Ratcliffe R.G. (1993) Quantitative aspects of the ${ }^{31} \mathrm{P}$ NMR detection of manganese in plant tissues. Journal of Experimental Botany 44, 1809-1818.

Rausch C., Daram P., Brunner S., Jansa J., Laloi M., Leggewie G., ..., Bucher M. (2001) A phosphate transporter expressed in arbuscule-containing cells in potato. Nature 414, 462-466.

Roby C., Martin J.B., Bligny R. \& Douce R. (1987) Biochemical changes during sucrose deprivation in higher plant cells $-\mathrm{P}^{31}$ Nuclear-Magnetic-Resonance studies. Journal of Biology and Chemistry 262, 5000-5007.

This article is protected by copyright. All rights reserved. 
Scheromm P., Plassard C. \& Salsac L. (1990) Effect of nitrate and ammonium nutrition on the metabolism of the ectomycorrhizal basidiomycete, Hebeloma cylindrosporum Romagn. New Phytologist 114, 227-234.

Smith S.E. \& Smith F.A. (1990) Structure and function of the interfaces in biotrophic symbioses as they relate to nutrient transport. New Phytologist 114, 1-38.

Smith S.E., Gianinazzi-Pearson V., Koide R. \& Cairney J.W.G. (1994) Nutrient transport in mycorrhizas: structure, physiology and consequences for efficiency of the symbiosis. Plant and Soil 159, 103-113.

Smith S.E \& Read D.J. (2008) Mycorrhizal Symbiosis. 3rd edition. Academic Press, London.

Smith S.E., Anderson I.C. \& Smith F.A. (2015) Mycorrhizal associations and phosphorus acquisition: from cells to ecosystems. Annual Plant Reviews 48, 409-440.

Solaiman M., Ezawa T., Kojima T. \& Saito M. (1999) Polyphosphates in intraradical and extraradical hyphae of an arbuscular mycorrhizal fungus, Gigaspora margarita. Applied and Environmental Microbiology 65, 5604-5606.

Tatry, M.-V., El Kassis, E., Lambilliotte, R., Corratge, C., van Aarle, I., Amenc, L.K., ..., Plassard C. (2009). Two differentially regulated phosphate transporters from the symbiotic fungus Hebeloma cylindrosporum and phosphorus acquisition by ectomycorrhizal Pinus pinaster. Plant Journal 57(6), 1092-1102.

Trilisenko L.V., Vagabov V.M. \& Kulaev I.S. (2002) The content and chain length of polyphosphates from vacuoles of Saccharomyces cerevisiae VKM Y-1173. Biochemistry (Moscow) 67, 592-596.

Vagabov, V.M., Trilisenko, L.V, Kulakovskaya, T.V. \& Kulaev, I.S. (2008). Effect of a carbon source on polyphosphate accumulation in Saccharomyces cerevisiae. Fems Yeast Research 8, 877-882.

Volpe, V., Giovannetti, M., Sun, X.-G., Fiorilli, V. \& Bonfante, P. (2016). The phosphate transporters LjPT4 and MtPT4 mediate early root responses to phosphate status in non mycorrhizal roots. Plant, Cell \& Environment 39, 660-71.

Wood H.G. \& Clark J.E. (1988) Biological aspects of inorganic polyphosphates. Annual Review of Biochemistry 57, 235-260. 


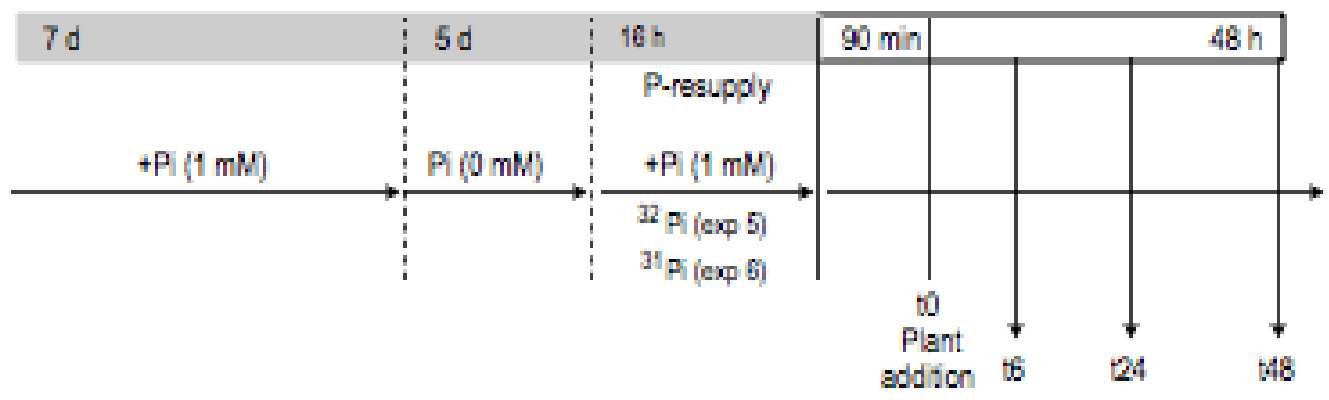

Figure 1. Experimental diagram of the plant interaction experiments.

Experiment 5 and 6 were run with ${ }^{32} \mathrm{P}$ labelled or ${ }^{31} \mathrm{P}$ non-labelled $H$. cylindrosporum mycelia, respectively. For both experiments, only P-starved mycelia were used. Mycelia were rinsed with IM for $90 \mathrm{~min}$ before addition of fresh IM $(60 \mathrm{ml})$ and plants into the syringes (t0). For each experiment, syringes (18 per period) were collected after 6 (t6), 24 (t24) and 48 (t48) h of incubation. For one experiment, 54 syringes were set up to receive 54 mycelia (one per syringe), 54 maize plants ( 3 seedlings per syringe x 6 replicates x 3 periods) and 54 pine plants (3 seedlings per syringe x 6 replicates $x 3$ periods). 
(b)
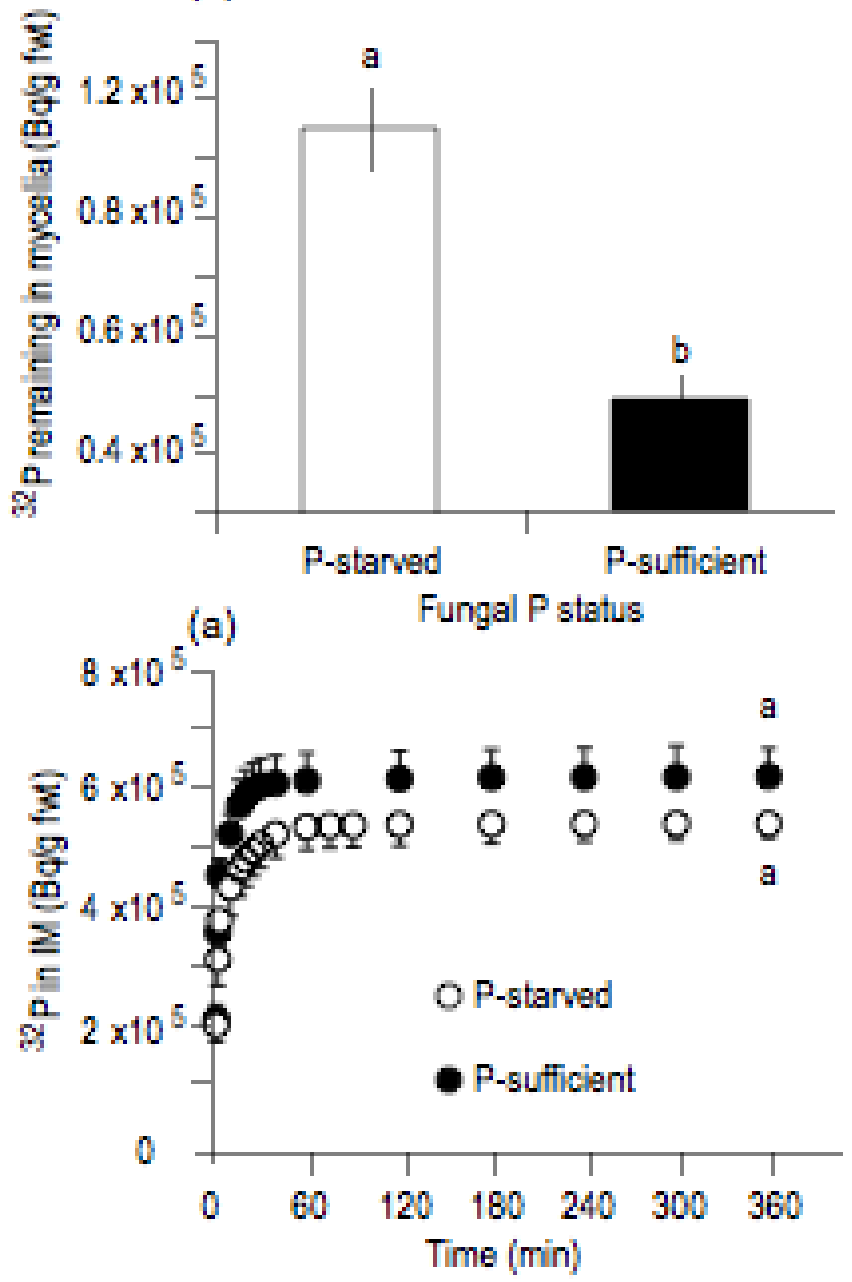

Figure 2. Fate of ${ }^{32} \mathrm{P}$ radioactivity $\left(\mathrm{Bq} \mathrm{g}^{-1}\right.$ fungal $\mathrm{FW}$ ) in $\mathrm{P}$-starved or $\mathrm{P}$-sufficient $H$. cylindrosporum mycelia after ${ }^{32} \mathrm{P}$-resupply.

(a) Cumulative amounts of radioactivity measured in the interaction medium (IM). (b) Amounts of radioactivity remaining in the mycelia at the end of the 360 min-rinsing period. The values are means with SEM ( $\mathrm{n}=6)$. Different letters denote significant differences between means at $p<0.05$ (one-way ANOVA, Tukey's post-hoc test).

Mycelia were grown in glass flasks (see Fig. S1) with nutrient solutions and conditions described for experiment 1 (see Fig. S2). 

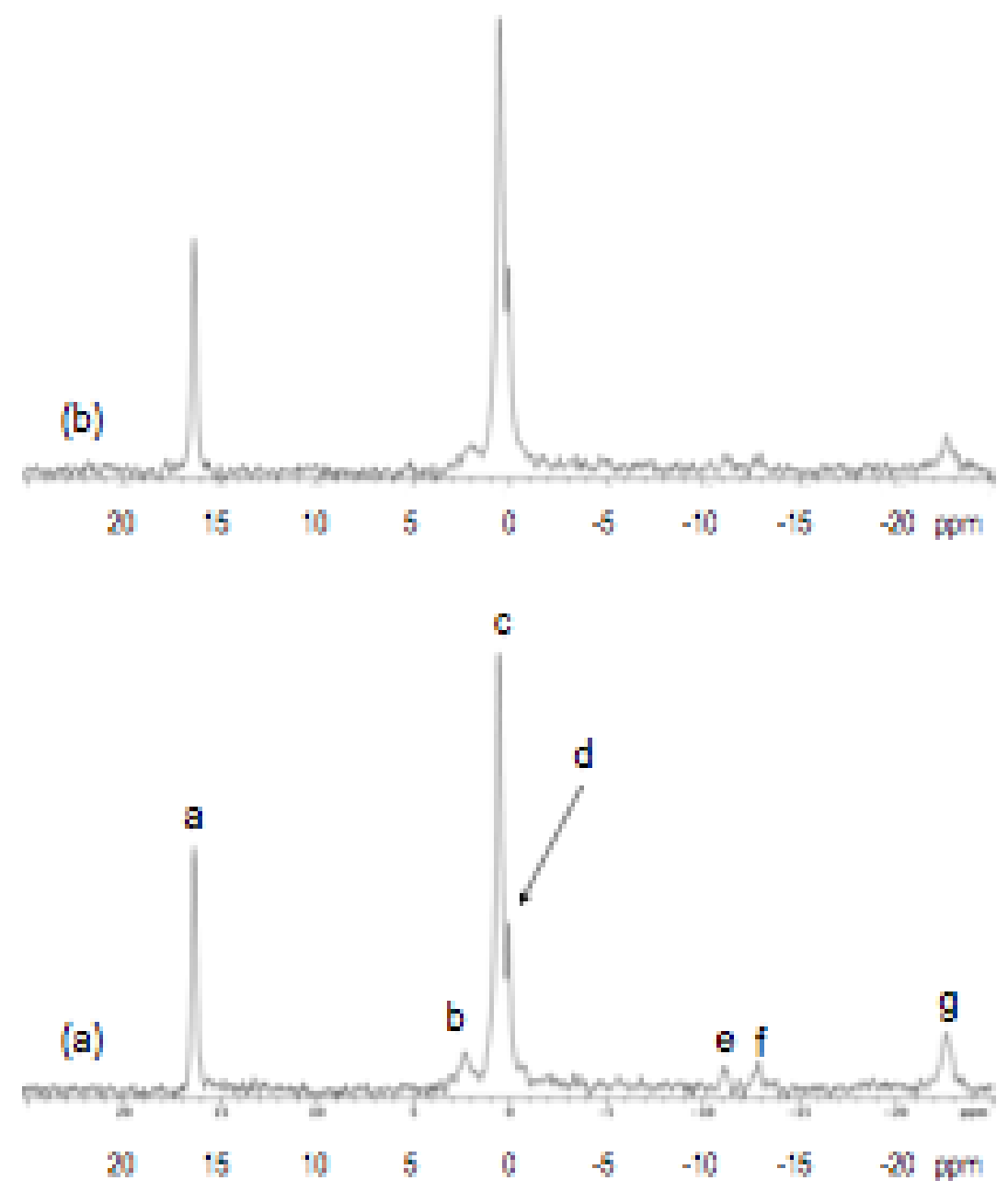

Figure 3. In vivo ${ }^{31} \mathrm{P}$ NMR spectra of $H$. cylindrosporum mycelia showing resonances for $\mathrm{Pi}$ and mobile polyP in P-starved (a) and P-sufficient (b) mycelia without P-resupply.

Peak assignments were as follows: a, external standard (MDP); b, cytoplasmic orthophosphate $(\mathrm{Pi})$; c, vacuolar $\mathrm{Pi}$; d, glycerophosphocholine; e, f, UDP-N-acetylglucosamine; g, soluble polyphosphate.

Mycelia were grown in glass flasks (see Fig. S1) with nutrient solutions and conditions described for experiment 2 (see Fig. S2). Spectra were recorded from six mycelia pooled together in the $10 \mathrm{~mm}-\mathrm{NMR}$ tube. 


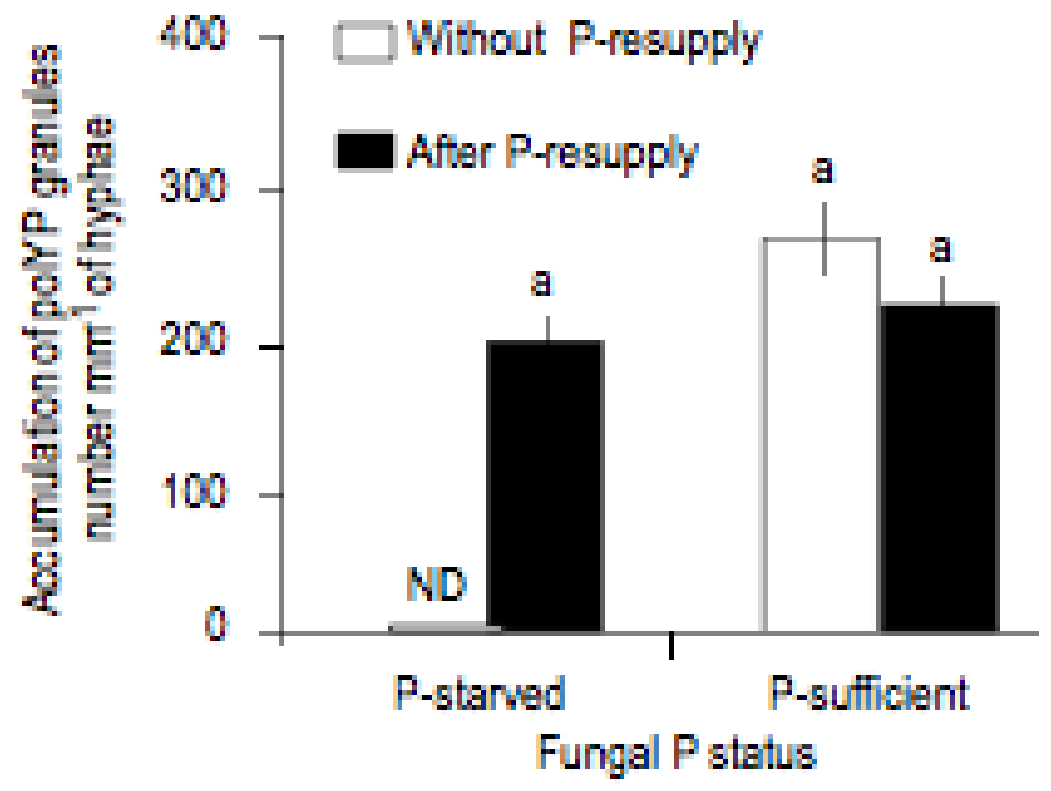

Figure 4. Number of polyP metachromatic granules in $\mathrm{P}$-starved and $\mathrm{P}$-sufficient $H$. cylindrosporum mycelia without P-resupply (white bars) and after P-resupply (black bars). Bars correspond to mean values with SE $(n=12)$. ND means not detected. Different letters denote significant differences at $P<0.05$

Mycelia were grown in glass flasks (see Fig. S1) with nutrient solutions and conditions described for experiment 4 (see Fig. S2). 


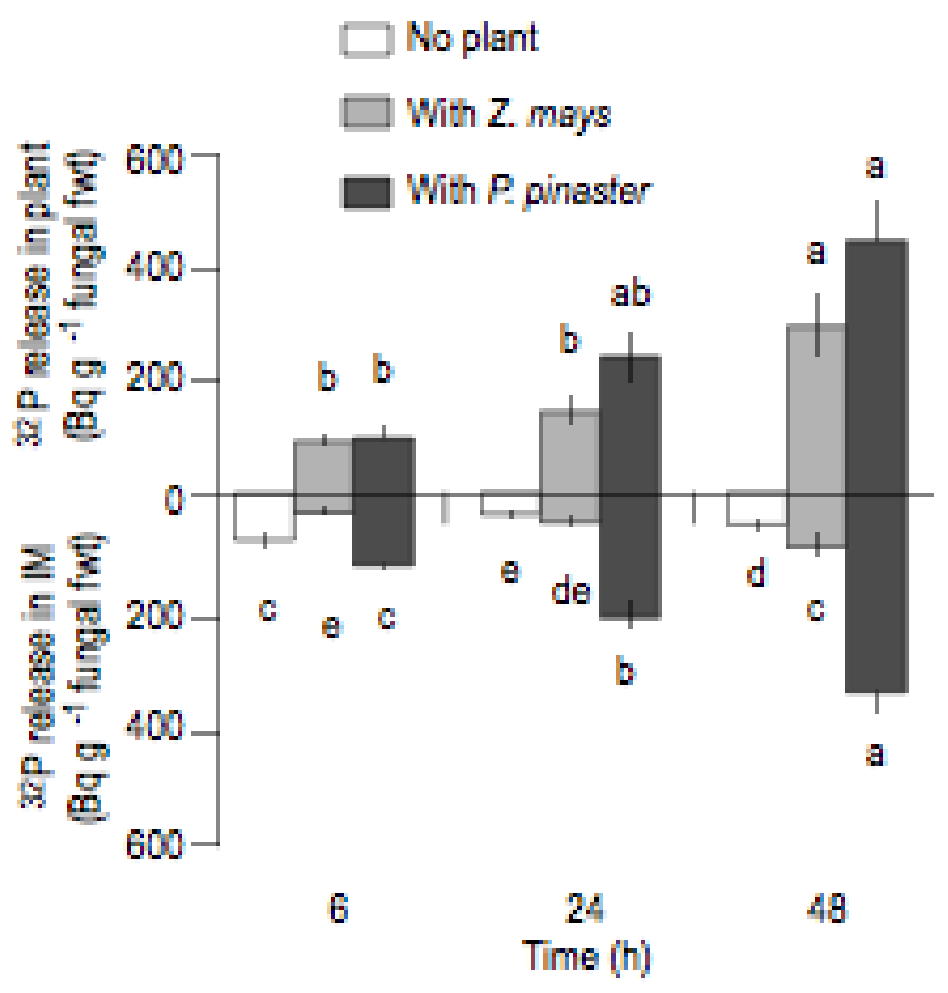

Figure 5. ${ }^{32} \mathrm{P}$ release by the ectomycorrhizal fungus $H$. cylindrosporum incubated with no plant or with $Z$. mays or $P$. pinaster and accumulated in plants (upper part) or in the IM (lower part). The amount of ${ }^{32} \mathrm{P}$ is expressed per gram of fungal FW. Error bars represent SE $(\mathrm{n}=6)$. Letters indicate significant differences $(P<0.05)$ between treatments (no plant, with Z. mays and with $P$. pinaster) and incubation time (6 h, $24 \mathrm{~h}$ and $48 \mathrm{~h})$.

Mycelia were prepared with nutrient solutions and conditions described in Fig. 1 (experiment $5)$. 

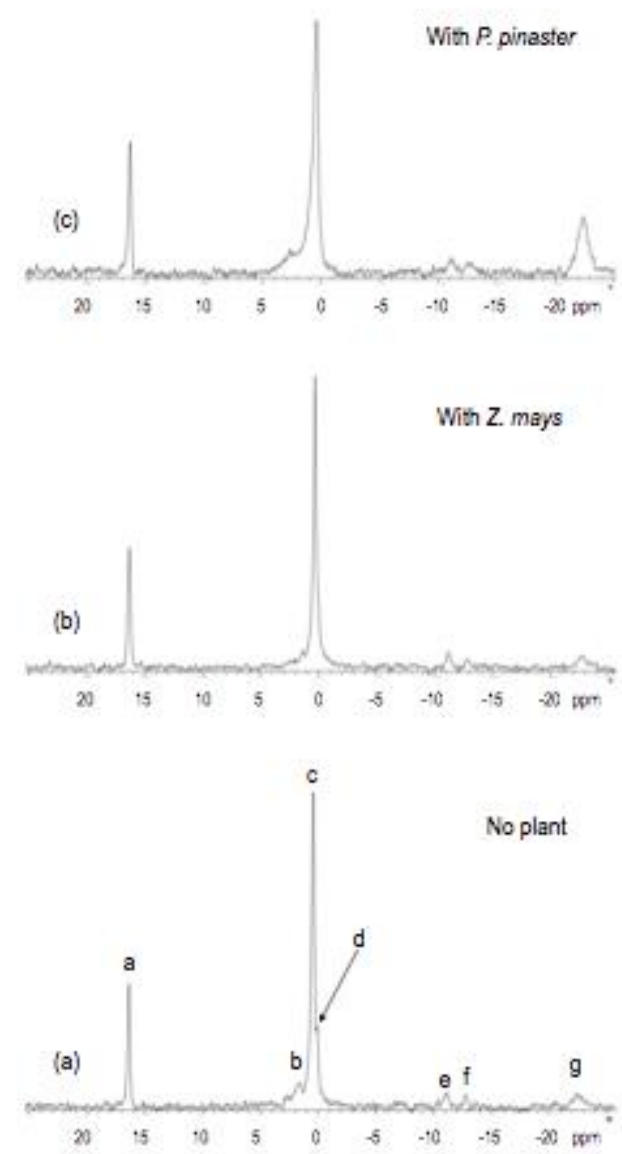

Figure 6. ${ }^{31} \mathrm{P}$ NMR spectra of $H$. cylindrosporum mycelium showing resonances from $\mathrm{Pi}$ and mobile polyP incubated with no plant (a) or with Z. mays (b) or P. pinaster (c).

Peak assignments were as follows: a, external standard (MDP); b, cytoplasmic orthophosphate $(\mathrm{Pi})$; c, vacuolar $\mathrm{Pi}$; d, glycerophosphocholine; e, f, UDP-N-acetylglucosamine; g, soluble polyphosphate. No glycerophosphocholine peak was observed in mycelia interacting with $P$. pinaster or $Z$. mays.

Mycelia were prepared with nutrient solutions and conditions described in Fig. 1 (experiment $6)$. 


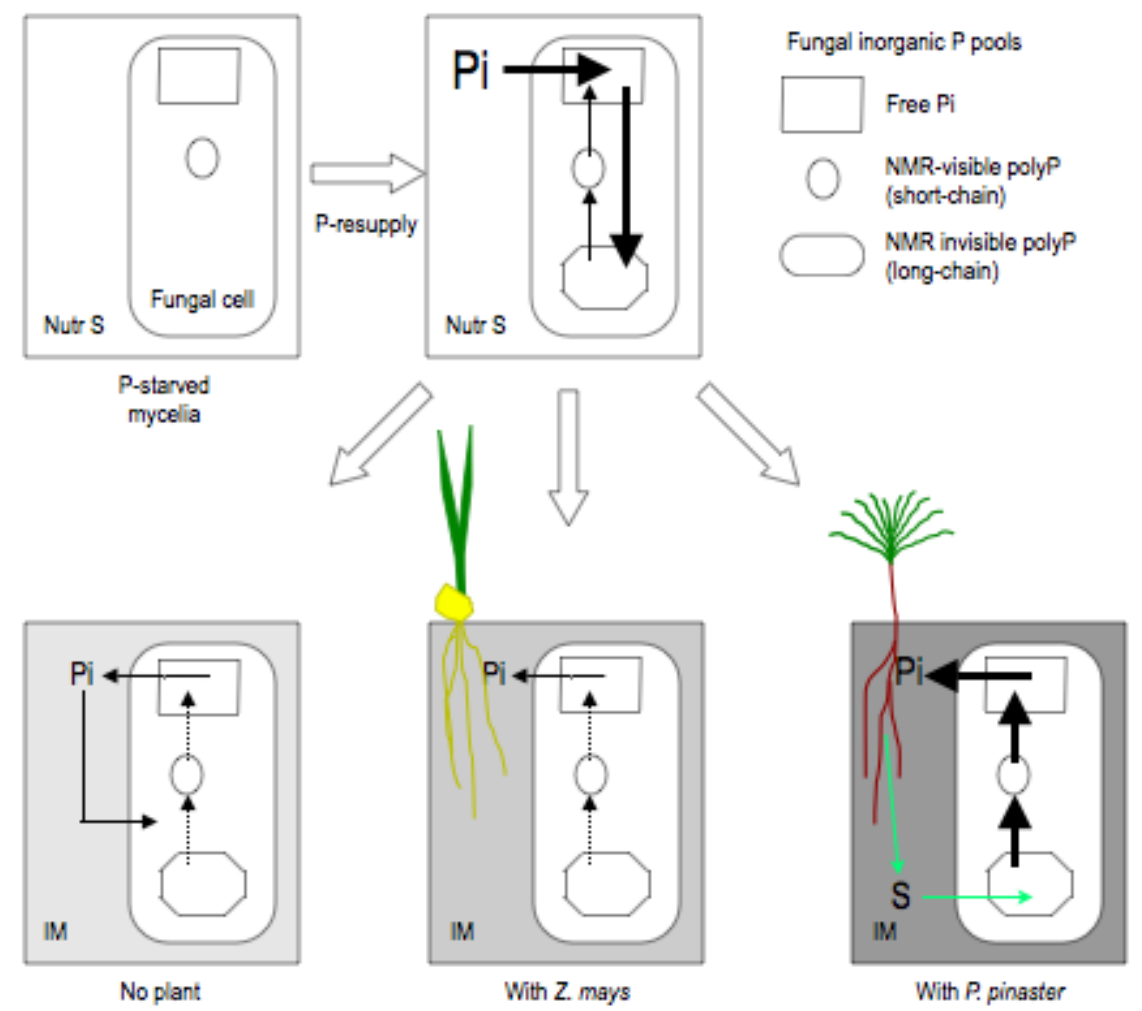

Figure 7. Schematic representation of the fate of Pi absorbed by P-starved mycelia during Presupply and subsequent incubation of mycelia in IM either alone (no plant), or with Z. mays or with $P$. pinaster roots.

The intensity of grey in IM denotes the amount of fungal ${ }^{32} \mathrm{P}$ measured after $48 \mathrm{~h}$ of incubation. The weight and width of each black arrow indicates the magnitude of fluxes between P pools. Nutr S: nutrient solution, IM: interaction medium, S: unknown soluble plant signal. 
Table 1. Proportion of NMR-visible polyphosphate (polyP) and cytoplasmic and vacuolar Pi (Pi) in $\mathrm{P}$-starved and $\mathrm{P}$-sufficient $H$. cylindrosporum mycelia determined from in vivo NMR ${ }^{31} \mathrm{P}$ spectra.

Mycelia were grown in glass flasks (see Fig. S1) with nutrient solutions and conditions described for experiment 2 (see Fig. S2).

$$
\text { Proportion (\%) in: }
$$

\begin{tabular}{llll}
\hline Time & Signal & P-starved mycelia & P-sufficient mycelia \\
\hline Without P-resupply & polyP & 14 & 11 \\
& $\mathrm{Pi}$ & 86 & 89 \\
\hline After P-resupply & polyP & 10 & 7 \\
& $\mathrm{Pi}$ & 90 & 93 \\
\hline
\end{tabular}


Table 2. Density of metachromatic granules (expressed in number of granules per mm of hyphae) in P-starved H. cylindrosporum mycelia transferred in a complete nutrient solution containing different $\mathrm{Pi}$ concentrations during $1 \mathrm{~h}$ or $16 \mathrm{~h}$ (P-resupply period). Values are means $\pm \operatorname{SEM}(n=12)$. Effect of Pi concentration and time were analyzed with one-way ANOVA.

Mycelia were grown in glass flasks (see Fig. S1) with nutrient solutions and conditions described for experiment 4* (see Fig. S2).

\begin{tabular}{llll}
\hline \multicolumn{4}{l}{ P concentration $(\mathrm{mM})$} \\
\hline Time (h) & 0.01 & 0.1 & $P$ \\
\hline 1 & $150 \pm 4$ & $151 \pm 3$ & $>0.05$ \\
16 & $206 \pm 13$ & $229 \pm 10$ & $>0.05$ \\
$P$ & 0.03 & 0.01 & \\
\hline
\end{tabular}


Table 3. Variation of $\mathrm{Pi}$ accumulation in visible signals of ${ }^{31} \mathrm{P}$ NMR spectra in $H$. cylindrosporum P-starved mycelia incubated with no plant or with Z. mays or P. pinaster. Peak areas are expressed as (a) the percentage of total area of NMR visible P or (b) relative to the reference peak of methyl diphosphonate (MDP). Means correspond to the average of values recorded after 6, 24 or $48 \mathrm{~h}$ and different letters denote significant differences between means (one-way ANOVA, Tukey's post-hoc test).

Mycelia were prepared with nutrient solutions and conditions described in Fig. 1 (experiment 6).

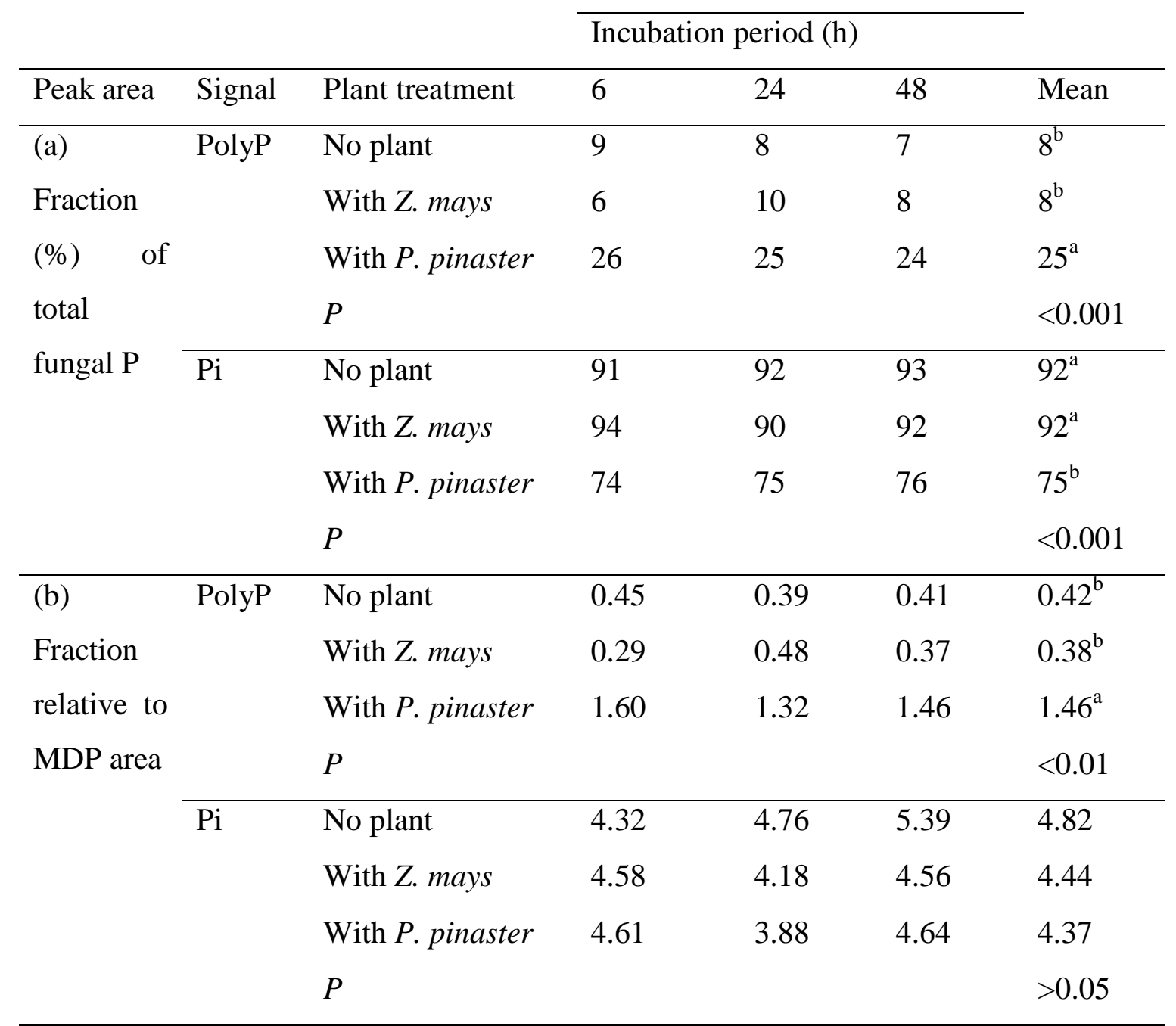

This article is protected by copyright. All rights reserved. 